\title{
Modeling of ammonothermal growth of gallium nitride single crystals
}

\author{
Q.-S. CHEN* \\ Institute of Mechanics, Chinese Academy of Sciences, 15 Bei Si Huan Xi Road, Beijing 100080, \\ China \\ E-mail: qschen@imech.ac.cn
}

S. PENDURTI, V. PRASAD

Department of Mechanical and Materials Engineering, Florida International University, $10555 \mathrm{~W}$

Flagler St., Miami, FL 33174, USA

Ammonothermal growth of GaN crystals with a retrograde solubility has been modeled and simulated here using fluid dynamics, thermodynamics and heat transfer models. The nutrient is considered as a porous media bed and the flow in the porous charge is simulated using the Darcy-Brinkman-Forchheimer model. The resulting governing equations are solved using the finite volume method. For the case of retrograde solubility, the charge is put above the baffle. The temperature difference between the dissolving zone and growth zone is found smaller than that applied on the sidewall of autoclave. The baffle opening has a strong effect on the nutrient transport and supersaturation of GaN species in the growth zone.

(C) 2006 Springer Science + Business Media, Inc.

\section{Introduction}

$\mathrm{GaN}$ and related materials can be used to fabricate blue/green/UV LEDs and LDs, and high temperature, high power electronic devices [1]. The LEDs can be used in cell phones and in the lighting and display equipments. LEDs can directly convert injected current into light and are very effective. GaN-based LEDs cover the expanded wavelength ranges from UV to IR. The nitrides also enable us to fabricate UV lasers, photodetectors, and high-power and high-speed transistors. For manufacture of LEDs and LDs, AlN or GaN substrates are lattice matched and isomorphic to nitride-based films. LEDs fabricated on sapphire substrates have a high dislocation density originating from a large lattice mismatch between $\mathrm{GaN}$ and sapphire substrates [2], and SiC substrates are expensive. In the past years, significant progress has been made to increase the size of nitride crystals.

Porowski [3] used the ultra high-pressure method to grow $\mathrm{GaN}$ single crystals from liquid $\mathrm{Ga}$ and $\mathrm{N}_{2}$. Nitrogen pressures were in the range of 12-20 kbar and temperatures were from $1400^{\circ} \mathrm{C}$ to $1700^{\circ} \mathrm{C}$. The nitrogen solubility in liquid gallium is in the order of $1 \%$ at 20 kbar. GaN plate-like single crystals of $100 \mathrm{~mm}^{2}$ size and good crystallographic quality have been grown. $\mathrm{Mg}$ - doped crystals were obtained by introduction of $\mathrm{Mg}$ into the growth solution.

Dwilinski et al. [4] obtained microcrystals of $\mathrm{BN}, \mathrm{AlN}$ and $\mathrm{GaN}$ by the ammonothermal method using lithium or potassium amide as mineralizer at pressures in the range of 1 to $5 \mathrm{kbar}$ and temperatures up to $550^{\circ} \mathrm{C}$.

Ketchum and Kolis [5] grew ammonothermal single crystals of gallium nitride in supercritical ammonia at $400^{\circ} \mathrm{C}$ and $2.4 \mathrm{kbar}$ by using potassium amide $\left(\mathrm{KNH}_{2}\right)$ and potassium iodide (KI) as mineralizers. Hexagonal GaN crystal of $0.5 \times 0.2 \times 0.1 \mathrm{~mm}^{3}$ was obtained. They have used potassium azide $\left(\mathrm{KN}_{3}\right)$ or sodium azide $\left(\mathrm{NaN}_{3}\right)$ as mineralizer to increase the solubility of $\mathrm{GaN}$ in ammonia.

Purdy et al. [6] grew both bulk cubic (zinc blende) and hexagonal $\mathrm{GaN}$ by ammonothermal reactions of gallium metal or $\mathrm{GaI}_{3}$ under acidic $\left(\mathrm{NH}_{4} \mathrm{Cl}, \mathrm{NH}_{4} \mathrm{Br}\right.$, or $\left.\mathrm{NH}_{4} \mathrm{I}\right)$ conditions. Gallium metal or compounds reacted slowly with supercritical $\mathrm{NH}_{3}$ in the presence of acidic mineralizer forming $\mathrm{GaN}$ of $0.1 \mathrm{~mm}$ size as the only crystalline product at temperatures from $250-500^{\circ} \mathrm{C}$ and pressure of 10,000 psi (0.6895 kbar).

Callahan et al. [7] found that $\mathrm{GaN}$ has a retrograde solubility in the ammonia if a mineralizer of $2-3 \mathrm{M} \mathrm{KNH}_{2}$ is used. Growth rate of 50-100 $\mu \mathrm{m} /$ day has been realized 
compared with commercial quartz growth rate of $0.5-$ $1 \mathrm{~mm} /$ day.

Aoki et al. [8] grew GaN single crystals with a maximum area of $3 \times 1.5 \mathrm{~mm}^{2}$ and thickness of $1.0 \mathrm{~mm}$ from seeds at $850^{\circ} \mathrm{C}$ and $2 \mathrm{MPa}$ of $\mathrm{N}_{2}$ for $200 \mathrm{~h}$ by using the $\mathrm{Na}$ flux method. The maximum growth rate in the $\mathrm{c}$ direction, about $4 \mu \mathrm{m} / \mathrm{h}$ at $850^{\circ} \mathrm{C}$ and $2 \mathrm{MPa}$ of $\mathrm{N}_{2}$, was higher than those in other directions and increased with growth temperature and $\mathrm{N}_{2}$ pressure. This group recently grew single crystals of $10 \mathrm{~mm}$ size by using the molten sodium under $30-50 \mathrm{~atm}$ of nitrogen gas and $200-400^{\circ} \mathrm{C}$. In these processes, sodium azide $\left(\mathrm{NaN}_{3}\right)$ and metallic gallium were used. The key to the success was to use the high purity metallic sodium (more than $99.95 \%$ ) and the high purity pyrolytic BN crucible instead of sintered BN. This enabled the suppression of the growth of fine crystals at the boundary between the gas and the liquid, leading to the large size crystals.

Iwahashi et al. [9] grew bulk GaN crystals by the Na flux method. By using nitrogen gas with $25-40 \%$ ammonia gas instead of pure nitrogen gas, the nucleation threshold pressure can be reduced from $30 \mathrm{~atm}$ to $10 \mathrm{~atm}$. Hereby, the reaction temperature was $800^{\circ} \mathrm{C}$.

We have modeled an ammonothermal system with an internal diameter of $0.932 \mathrm{~cm}$ in [10] and found that the particle size greatly affects the nutrient transport. In [11], we considered an autoclave with an internal diameter of $2.22 \mathrm{~cm}$ and discussed the effects of the baffle design and opening on the nutrient transport. In this paper, we will consider the ammonothermal growth of $\mathrm{GaN}$ with a retrograde solubility in ammonia. The purpose of this article is to determine the effects of the baffle opening on the fluid flow pattern and temperature distribution around the baffle in the case of retrograde solubility. The particle charge is considered as a porous media bed, and the flow in the porous charge is simulated using the Darcy-BrinkmanForchheimer model.

\section{Physical and mathematical model}

\subsection{Experimental setup}

The ammonothermal technique is an important method among others with promise of commercially available growth rates and material quality. In the ammonothermal growth, ammonia is used as the solvent rather than water as in the hydrothermal process. A combination of mineralizers, such as amide, or azide, is used to attack a bulk nitride feedstock at temperatures from $200-500^{\circ} \mathrm{C}$ and pressures from 1-4 kbar. Solubility of $\mathrm{GaN}$ in ammonia can be up to $1-4 \%$ in weight using potassium amide as mineralizer [5].

For the ammonothermal growth of $\mathrm{GaN}$ with a retrograde solubility, the predetermined amount of GaN particles are loaded above the baffle inside an autoclave (see Fig. 1). GaN seeds are hanged on a wire below

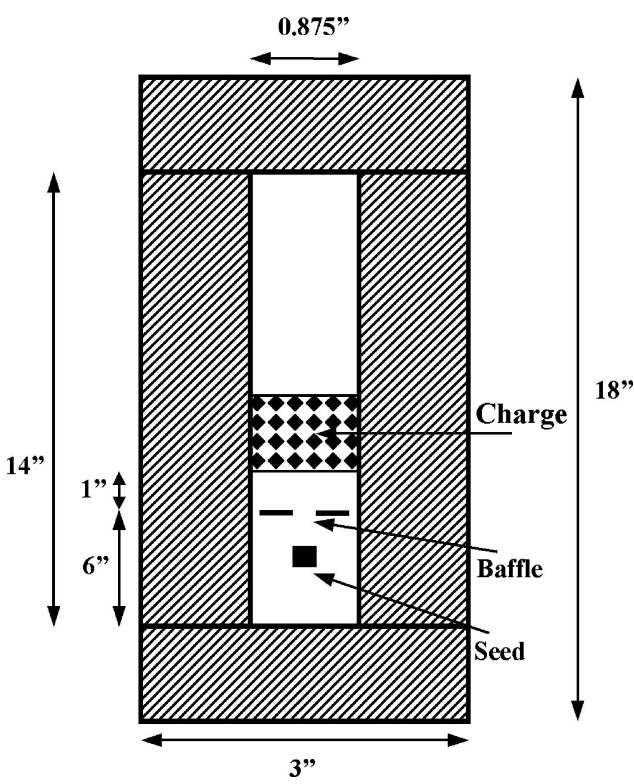

Figure 1 Schematic of an ammonothermal growth system.

the baffle. The baffle separates the growth zone from the dissolving zone to maintain a temperature difference between the two zones or a supersaturation of $\mathrm{GaN}$ species in the growth zone. The baffle opening is used to control the mixing of nutrients in the two zones, thus the transfer of nutrient from the upper part to the lower part.

If the solubility of $\mathrm{GaN}$ has a negative coefficient with respect to temperature, the growth zone in the lower part has to be maintained at a higher temperature than that in the upper part. After loading the ammonia and mineralizers in the autoclave, a temperature gradient is applied on the sidewall of the autoclave, e.g., $300-250^{\circ} \mathrm{C}$ from the bottom to the top of the sidewall. A pressure of 2-4 kbar can be obtained with a 70$90 \% \mathrm{NH}_{3}$ fill [5]. The critical properties of ammonia are $T_{c}=405.5 \mathrm{~K}$, and $P_{c}=112.8$ bar [12]. The reduced pressure and reduced temperature under typical ammonothermal growth conditions, e.g., 2000 bar and $250^{\circ} \mathrm{C}$, are $P_{r}=2000 / 112.8=17.7, T_{\mathrm{r}}=523 / 405.5=1.3$, respectively. For $P_{r}=10$, and $T_{r}=1.3$, the viscosity and conductivity of ammonia are $\mu / \mu_{1}=4.3, \mathrm{k} / \mathrm{k}_{1}=5.0$, respectively, where $\mu_{1}$ and $\mathrm{k}_{1}$ are the dynamic viscosity, and thermal conductivity at atmospheric pressure and $250^{\circ} \mathrm{C}$ [12].

\subsection{Process modeling}

After the ammonothermal system is pressurized, ammonia occupies most of the volume. Hence the upper portion can be considered as a fluid layer with the assumption of incompressible flow and the Boussinesq approximation, which assumes that the density is a function of temperature in the buoyancy term while is constant in other terms of the Navier-Stokes equations [13]. The GaN particles in 


\section{A NOVEL METHOD OF ADVANCED MATERIALS PROCESSING}

the bottom of the autoclave can be considered as a porous medium. The Darcy-Brinkman-Forchheimer model is employed in the porous layer, while Navier-Stokes equations are used in the fluid layer. The dimensionless parameters of the system are listed below:

$$
\begin{aligned}
\operatorname{Ar}=H /(2 R), G r & =g \beta R^{3} \Delta T / v^{2}, \\
\operatorname{Pr} & =v / \alpha, \\
\mathrm{Da}=K / R^{2}, \mathrm{Fs} & =b / R,
\end{aligned}
$$

where $A r, \mathrm{Gr}, \mathrm{Pr}, \mathrm{Da}$, Fs denote aspect ratio, Grashof number, Prandtl number, Darcy number, and Forchheimer number, respectively. $H$ is the internal height of the autoclave, $R$ is the internal radius of the autoclave, $g$ is the acceleration due to gravity, $\beta$ is the isobaric coefficient of expansion, $\Delta T$ is the maximum temperature difference on the sidewall of the autoclave, $v$ is kinematic viscosity, and $\alpha$ is thermal diffusivity. The permeability of porous matrix $K=d_{p}^{2} \varepsilon^{3} /\left[150(1-\varepsilon)^{2}\right]$ with $d_{p}$ as the average diameter of the nutrient particles, and the Forchheimer coefficient $b=1.75 K^{0.5} /\left(\sqrt{150} \varepsilon^{1.5}\right)$.

The governing equations in the porous and fluid layers can be combined by defining a binary parameter $B$ as: $B=0$ in the fluid layer and $B=1$ in the porous layer, respectively. The porosity $\varepsilon=0$ in solid, $0<\varepsilon<1$ in porous layer and $\varepsilon=1$ in fluid layer, respectively. The combined governing equations in a cylindrical coordinate system are:

$$
\begin{gathered}
\frac{\partial\left(\varepsilon \rho_{f}\right)}{\partial t}+\nabla \cdot\left(\rho_{f} \mathbf{u}\right)=0 \\
\frac{\rho_{f}}{\varepsilon} \frac{\partial \mathbf{u}}{\partial t}+\frac{\rho_{f}}{\varepsilon}(\mathbf{u} \cdot \nabla) \frac{\mathbf{u}}{\varepsilon}=-\nabla p+\rho_{f} g \mathbf{z} \\
+\nabla \cdot\left(\mu_{e} \nabla \boldsymbol{u}\right)-B\left[\left(\frac{\mu_{f}}{K}+\frac{\rho_{f} b}{K}|\mathbf{u}| \mathbf{u}\right)\right], \\
\left(\rho c_{p}\right)_{e} \frac{\partial T}{\partial t}+\left(\rho c_{p}\right)_{f}[(\mathbf{u} \cdot \nabla) T] \\
=\nabla \cdot\left(k_{e} \nabla T\right)
\end{gathered}
$$

where $\rho, k, c_{p}$ denote density, thermal conductivity, and specific heat, respectively. $\mathbf{z}$ is the unit vector in the $\mathrm{z}$ direction. Subscript $\mathrm{f}$, e denote fluid and effective, respectively.

To non-dimensionalize the governing equations, the reference length, time, velocity and pressure scales are set as $R, t_{0}=R^{2} / v, u_{0}=v / R$ and $P_{0}=p v^{2} / R^{2}$, respectively. The non-dimensional coordinates, velocities, pressure and temperature are defined as, $r^{\prime}=r / R$, $z^{\prime}=z / R, u^{\prime}=u / u_{0}, w^{\prime}=w / w_{0}, p^{\prime}=p / p_{0}$, and $\Theta=\left(T-T_{L}\right) /\left(T_{H}-T_{L}\right)$ where $T_{H}$ and $T_{L}$ are the high temperature and low temperature applied on the sidewall of the autoclave. In the following analysis, we omit the prime' for simplicity. The resulting non-dimensionalized equations are,

$$
\begin{gathered}
\frac{\partial \varepsilon}{\partial t}+\frac{1}{r} \frac{\partial}{\partial r}(r u)+\frac{\partial}{\partial z}(w)=0, \\
\frac{\partial}{\partial t}\left(\frac{1}{\varepsilon} u\right)+\frac{1}{r} \frac{\partial}{\partial r}\left(\frac{1}{\varepsilon^{2}} r u u\right)+\frac{\partial}{\partial z}\left(\frac{1}{\varepsilon^{2}} w u\right) \\
=\bar{u}\left[\frac{1}{r} \frac{\partial}{\partial r}\left(r \frac{\partial u}{\partial r}\right)+\frac{\partial^{2} u}{\partial z^{2}}-\frac{u}{r^{2}}\right] \\
-\frac{\partial p}{\partial r}-B\left(\frac{1}{\operatorname{ReDa}}+\frac{\mathrm{Fs}}{\mathrm{Da}}|\mathbf{u}|\right) u, \\
\frac{\partial}{\partial t}\left(\frac{1}{\varepsilon} w\right)+\frac{1}{r} \frac{\partial}{\partial r}\left(\frac{1}{\varepsilon^{2}} r u w\right)+\frac{\partial}{\partial z}\left(\frac{1}{\varepsilon^{2}} w w\right) \\
=\bar{\mu}\left[\frac{1}{r} \frac{\partial}{\partial r}\left(r \frac{\partial w}{\partial r}\right)+\frac{\partial^{2} w}{\partial z^{2}}\right] \\
-\frac{\partial p}{\partial z}+G r \theta-B\left(\frac{1}{\operatorname{ReDa}}+\frac{F s}{D a}|\mathbf{u}|\right) w, \\
\overline{\rho c} \frac{\partial}{\partial t}(\Theta)+\frac{1}{r} \frac{\partial}{\partial r}(r u \Theta)+\frac{\partial}{\partial z}(w \Theta) \\
=\frac{1}{\operatorname{Pr}} \bar{k}\left[\frac{1}{r} \frac{\partial}{\partial r}\left(r \frac{\partial \Theta}{\partial r}\right)+\frac{\partial}{\partial z}\left(\frac{\partial \Theta}{\partial z}\right)\right],
\end{gathered}
$$

where $\bar{\rho}=\frac{\rho_{e}}{\rho_{f}}, \bar{\mu}=\frac{\mu_{e}}{\mu_{f}}, \bar{c}_{p}=\frac{c_{p} e}{c_{p} f}, \bar{k}=\frac{k_{e}}{k_{f}}$.

The momentum equations $(3 \mathrm{~b}, \mathrm{c})$ and energy equation (3d) are solved using an in-house developed finite volume algorithm [13]. The above conservation equations (3b-d) can be written in the following general form:

$$
\begin{array}{r}
\frac{\partial}{\partial t}(r c \phi)+\frac{1}{r} \frac{\partial}{\partial r}(d r u \phi)+\frac{\partial}{\partial z}(d w \phi) \\
B=\frac{\partial}{\partial r}\left(r \Gamma \frac{\partial \phi}{\partial r}\right)+\frac{\partial}{\partial z}\left(r \Gamma \frac{\partial \phi}{\partial z}\right)+r\left(S_{c}+S_{p} \phi\right),
\end{array}
$$

where $\phi$ is the generalized variable, $\Gamma$ is the diffusion coefficient, and $S_{C}$ is the volumetric source. The coefficients are defined as $c=\frac{1}{\varepsilon}, d=\frac{1}{\varepsilon^{2}}, \Gamma=\bar{\mu}$, $S_{C}=-\frac{\partial p}{\partial r}$, and $S_{P}=-B\left(\frac{1}{\mathrm{ReDa}}+\frac{\mathrm{Fs}}{\mathrm{Da}}|\mathbf{u}|\right)-\frac{1}{r^{2}}$ for Eq. (3b) $(\phi=u) ; c=\frac{1}{\varepsilon}, d=\frac{1}{\varepsilon^{2}}, \Gamma=\bar{\mu}, S_{C}=$ $-\frac{\partial p}{\partial z}+G r \Theta$ and $S_{P}=-B\left(\frac{1}{\mathrm{ReDa}}+\frac{\mathrm{Fs}}{\mathrm{Da}}|\mathbf{u}|\right)$ for Eq. (3c), $(\phi=w), c=\bar{\rho} \bar{c}_{p} d=1, \Gamma=\frac{\bar{k}}{\operatorname{Pr}}, S_{C}=0$, and $S_{P}=0$ for Eq. (3d), $(\phi=\Theta)$.

A temperature profile is set on the sidewall of the autoclave, $T=T_{H}$ for $z<H_{B}-0.5 \delta_{T} ; T=T_{H}-\left(T_{H}-T_{L}\right)[z-$ $\left.\left(H_{B}-0.5 \delta_{T}\right)\right] / \delta_{T}$ for $H_{B}-0.5 \delta_{T} \leq z \leq H_{B}+0.5 \delta_{T}$; for $T=T_{L}$ for $z>H_{B}+0.5 \delta_{T}$, where $H_{\mathrm{B}}$ is the height of 
the baffle, and $\delta_{\mathrm{T}}$ is the height of the wall where the temperature changes from $T_{H}$ to $T_{L}$. The top and bottom of the autoclave are considered adiabatic. The temperature distribution is considered axisymmetric, $\frac{\partial T}{\partial r}=0$, at $r=0$.

For solving the momentum equations and the pressure equation inside the autoclave, we search the fluid boundaries inside the autoclave in the $r$ and $z$ directions, respectively. For example, when solving the equations using the TDMA method, we search the fluid boundaries in $r$ or $z$ direction separately, and solve the equations in this direction in different intervals of fluid space. This way, we can obtain the fluid field inside the autoclave that contains different shapes of baffles and seeds. For solving the temperature equation, the computational domain includes the autoclave and the charge inside the autoclave. The mesh size of $76 \times 222$ in radial and vertical directions is used in the simulation, and the time step is $d t / t_{0}=10^{-6}$.

\section{Results and discussion}

By using a mineralizer of $2-3 \mathrm{M} \mathrm{KNH}_{2}$, the $\mathrm{GaN}$ has a retrograde solubility in ammonia as described in [7]. The solubility of GaN in ammonia changes from $10 \%$ in weight to $2 \%$ if temperature increases from $350^{\circ} \mathrm{C}$ to $600^{\circ} \mathrm{C}$. With a fill of $60-85 \%$ and temperature of $600^{\circ} \mathrm{C}$, pressure is in the range of 25-45 kpsi (1.72-3.10 kbar). A typical run takes 14-21 days and growth was observed both on the seeds and on walls of the autoclave. We consider a case in which the autoclave has an internal diameter of 0.875 inch $(2.22 \mathrm{~cm})$, external diameter of 3 inch $(7.62 \mathrm{~cm})$, internal height of 14 inch $(35.56 \mathrm{~cm})$ and external height of 15 inch $(38.1 \mathrm{~cm})($ Tem-Press MRA 378R with a volume of $134 \mathrm{ml}$ ). The thickness of the sidewall of the autoclave is 1 inch. The baffle is located at a distance of 6 inch from the bottom of the autoclave. The charge of 4 inch in height is put 1 inch above the baffle, and the charge particle size is $0.6 \mathrm{~mm}$. $\Delta T$ applied on the sidewall is $50 \mathrm{~K}$. The baffle is $0.28 \mathrm{~mm}$ in thickness. The aspect ratio, Grashof number, Prandtl number, Darcy number and Forchheimer number are, $A r=16, \mathrm{Gr}=6$. $0 \times 10^{7}, \mathrm{Pr}=0.73, \mathrm{Da}=3.8 \times 10^{-6}$, and $\mathrm{Fs}=1.1 \times$ $10^{-3}$, respectively. The reference velocity and time scales are $u_{0}=1.4 \times 10^{-5}$ and $t_{0}=748 \mathrm{~s}$.

Fig. 2a shows the flow pattern in the growth system with a retrograde solubility of GaN. The baffle openings are $15 \%$ in cross-sectional area including $10 \%$ in the central hole and $5 \%$ in the ring opening between the baffle and the sidewall of autoclave. Since the GaN charge is put above the baffle, the fluid flow is much stronger below the baffle as shown in Fig. 2a. Highly oscillatory flow is observed across the central hole in the baffle. The flow in the central hole first moves downwards sending nutrient to the growth zone down to the bottom of the autoclave, then the flow moves upwards sending ex-

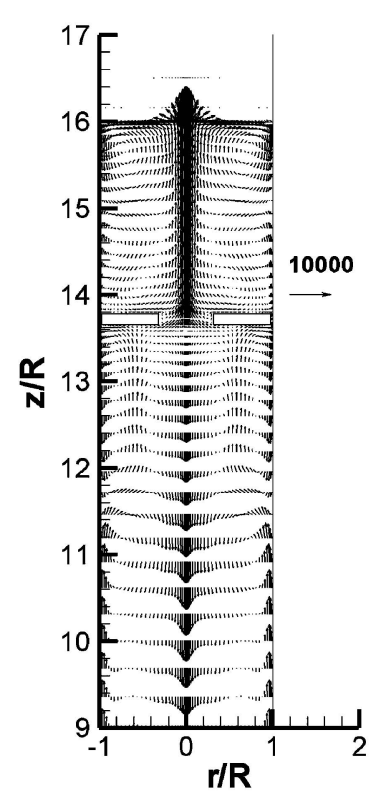

(a)

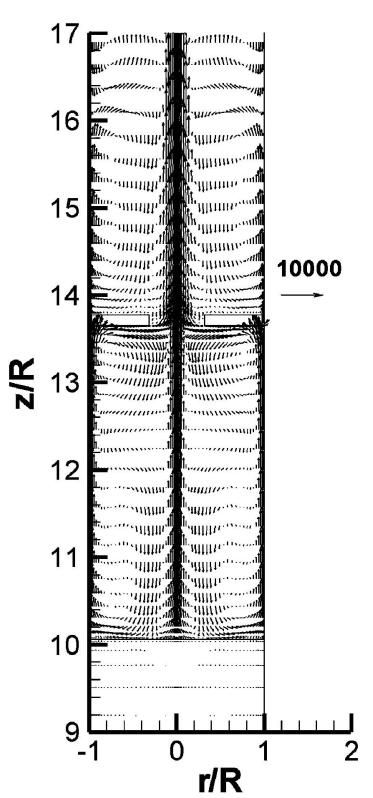

(b)
Figure 2 (a) Fluid flow in an ammonothermal system with a retrograde solubility, (b) fluid flow with a forward solubility. Baffle opening is chosen as $15 \%$ in cross-sectional area (central opening of $10 \%$ and ring opening of $5 \%$.

hausted fluid back to the dissolving zone up to the porous layer. This process repeats with time. The opening of $15 \%$ causes very large flow oscillations across the baffle in this case.

For comparison, we also plotted the flow pattern in the growth system with a forward solubility in Fig. $2 b$. The flow is weak below the baffle, and almost diminished in the porous layer. The modified Grashof number can be used to measure the flow strength in the porous charge, $\mathrm{Gr}^{*}=\mathrm{Gr} \cdot \mathrm{Da}$. In this case, the modified Grashof number is $\mathrm{Gr}^{*}=228$. Thus, the heat and mass transfer in the porous layer is determined mainly by conduction and diffusion, which may constraint the transport of nutrient between the charge and the fluid layer.

The temperature distribution profile for the case of retrograde solubility is shown in Fig. 3a. The temperature difference between the dissolving zone and growth zone is smaller than that applied on the sidewall of autoclave. The temperature gradient is large across the baffle, which may cause some depositions of GaN near the baffle. The baffle opening is used to control the mixing of the nutrient in two zones, thus cause the nutrient transfer from the lower part to the upper part. A larger baffle opening means more fluid mixing across the baffle and less temperature difference between two zones. In this case, the temperature across the baffle oscillates with time, and the magnitude of oscillation of temperature is very large for the baffle opening of $15 \%$.

Fig. 3b shows the temperature distribution with a forward solubility in which case the charge is put below the baffle. Large temperature gradient exists at the 


\section{A NOVEL METHOD OF ADVANCED MATERIALS PROCESSING}

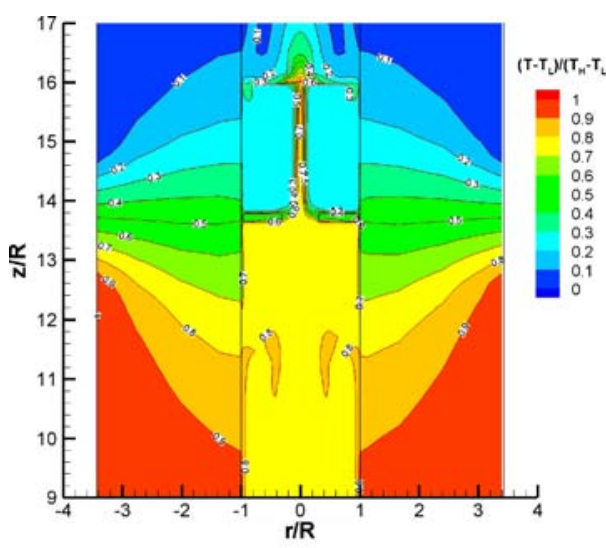

(a)

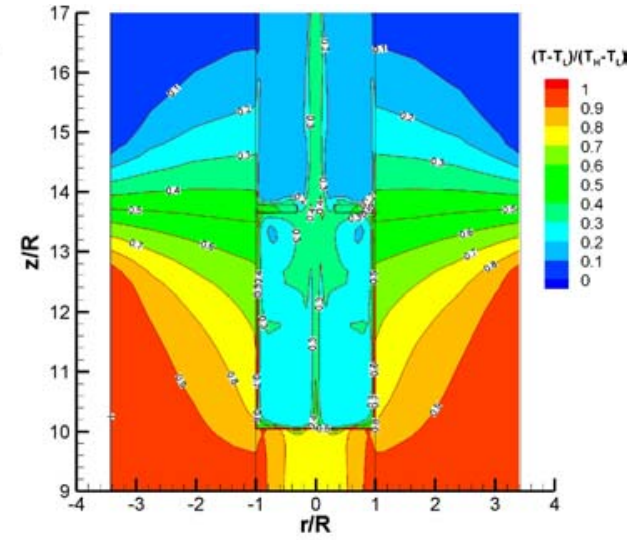

(b)

Figure 3 (a) Temperature distribution profile in an ammonothermal system with a retrograde solubility, (b) temperature distribution profile with a forward solubility. Baffle opening is $15 \%$ in cross-sectional area (central opening of $10 \%$ and ring opening of $5 \%$.

fluid/charge interface, which may cause deposition near the interface. In the case of retrograde solubility, the flow field and thermal field are totally different from that in the case of forward solubility. Despite from the solubility factor, other factors such as baffle opening and nutrient size, are also important for a successful growth of large size GaN ammonothermal crystals. The constraints for the ammonothermal growth include dissolving of charge, nucleation on the sidewall, transfer of nutrient from charge to seed, and growth kinetics. The mass transfer between the charge and the fluid layer is important for the continued growth of GaN crystals. The flow strength in the fluid layer depends on the Grashof number, which is proportional to the temperature difference on the sidewall and the cube of the internal radius of the autoclave. Flow in the charge layer depends on the modified Grashof number, i.e., the product of Grashof number and Darcy number, which is proportional to the square of the average diameter of particles. The flow strength in the porous layer can be increased by increasing the size of particles, or by putting particles in bundles as in the hydrothermal growth.

\section{Conclusions}

An ammonothermal growth system with a retrograde solubility is considered here in which the autoclave used has an internal diameter of 0.875 inch $(2.22 \mathrm{~cm})$, and internal height of 14 inch $(35.56 \mathrm{~cm})$. The baffle opening is chosen as $15 \%$ in cross-sectional area. It is found that the fluid field and temperature distribution are different from that in the case of forward solubility. The flow is much stronger in the lower part of the autoclave in the case of retrograde solubility. The temperature difference between the dissolving zone and growth zone is smaller than that applied on the sidewall of autoclave. The temperature gradients across the baffle are large which may cause some depositions of GaN near the baffle. The baffle opening is selected to achieve a certain temperature difference across the baffle, and thus certain supersaturation in the lower part of the autoclave and growth rate of crystals can be achieved. The fluid flow and temperature field across the baffle oscillate with time, and the magnitude of the temperature oscillation is very large for the baffle opening of $15 \%$.

\section{Acknowledgments}

The research was supported by the National Science Foundation of China (10472126) and the Knowledge Innovation Program of Chinese Academy of Sciences. The authors would like to thank Dr M. Callahan in the Air Force Research laboratory at Hanscom for helpful discussions.

\section{References}

1. S.J. PEARTON, R.J. SHUL and F. REN, MRS Internet J. Nitride Semiconductor Res. 5 (2000) 11.

2. S. NAKAMURA, M. SENOH, S. NAGAHAMA, N. IWASA, T. MATUSHITA and T. MUKAI, MRS Internet J. Nitride Semiconductor Res. 4S1 (1999) G1.1.

3. S. POROW K I, MRS Internet J. Nitride Semiconductor Res. 4S1 (1999) G1.3.

4. R. DWILINSKI, R. DORADZINSKI, J. GARCZYNSKI, L. SIERZPUTOWSKI, M. PALCZEWSKA, A. WYSMOLEK and M. KA MINS K A, MRS Internet J. Nitride Semiconductor Res. 3 (1998) 25.

5. D. R. KetChuM and J. W. KOLIS, J. Crystal Growth 222 (2001) 431.

6. A.P. PURDY, S. CASE and N. MURATORE, J. Crystal Growth 252 (2003) 136.

7. M. CALLAHAN, K. RAKES, D. BLISS, L. Bouthillette, M. SUSCAVAGE, B. WANG and S.Q. WANG, GaN Single Crystals Grown on HVPE Seeds in Alkaline Supercritical Ammonia, to be published in the Journal of Materials Science. 


\section{A NOVEL METHOD OF ADVANCED MATERIALS PROCESSING}

8. M. AOKI, H. YAMANE, M. SHIMADA, S. SARAYAMA and F. J. DIS ALVO, Materials Letters 56 (2002) 660.

9. T. IWAHASHI, F. KAWAMURA, M. MORISHITA, Y. KAI, M. YOSHIMURA, Y. MORI and T. SASA KI, J. Crystal Growth 253 (2003) 1.

10. Q.-S. CHEN, V. PRASAD and W.R. HU, J. Crystal Growth 258 (2003) 181

11. Q.-S. CHEN, S. PENDURTI and V. PRASAD, J. Crystal Growth 266 (2004) 271.
12. A. J. CHAPMAN, Heat Transfer, Macmillan Publishing Company, New York, 1984

13. Q.-S. CHEN, V. PRASAD and A. CHATTERJEe, J. Heat Transfer 121 (1999) 1049

Received 20 December 2004 and accepted 09 April 2005 